\author{
ADAM PIETRZYKOWSKI \\ Uniwersytet im. Adama Mickiewicza \\ w Poznaniu
}

\title{
ROLA OTWARTYCH ZASOBÓW EDUKACYJNYCH W KSZTAŁTOWANIU NOWEGO PARADYGMATU W EDUKACJI
}

\begin{abstract}
Pietrzykowski Adam, Rola otwartych zasobów edukacyjnych w kształtowaniu nowego paradygmatu $w$ edukacji [The role of open educational resources in shaping a new paradigm in education]. „Neodidagmata” 35, Poznań 2013, Adam Mickiewicz University Press, pp. 135-143. ISBN 978-
\end{abstract} 83-232-2685-7. ISSN 0077-653X.

Education is in a state of paradigm shift. Both its socio-cultural and technological dimensions are constantly changing at an unprecedented speed. As a result, the whole educational universe is going through a transformation that leads to a "new educational order". One of the essential elements that influence its shape is undoubtedly the phenomenon of open educational resources, which seem to play a particularly multifaceted role.

Adam Pietrzykowski, Uniwersytet im. Adama Mickiewicza w Poznaniu, Wydziat Nauk Społecznych, Instytut Kulturoznawstwa, ul. Szamarzewskiego 89, 60-568 Poznań, Polska - Poland.

Współcześnie edukacja znajduje się $\mathrm{w}$ stadium paradygmatycznej zmiany. Zarówno bowiem warstwa społeczno-kulturowa, jak i oddziałująca na nią warstwa technologiczna podlegają nieustannym zmianom o niespotykanej wcześniej dynamice. Sytuacja ta spowodowała, iż całe edukacyjne uniwersum przechodzi właśnie transformację prowadzącą do ukształtowania się "nowego ładu edukacyjnego". Jednym z istotnych elementów współkonstytuujących jego kształt jest bez wątpienia fenomen otwartych zasobów edukacyjnych, których rola w tym zakresie wydaje się szczególnie wieloaspektowa.

\section{PARADYGMAT A EDUKACJA}

Przyjęta $\mathrm{w}$ tytule artykułu teza wymaga precyzyjnej definicji zastosowanych pojęć. Zwłaszcza zaś pojęć paradygmatu i edukacji, które definio- 
wane mogą być na wiele różnych sposobów. Pojęcie paradygmatu w sensie potocznym stosuję się zazwyczaj jako pewnego rodzaju typ idealny służący do określenia zbioru intersubiektywnie uznawalnych przekonań odnośnie jakiegoś zagadnienia. Zostało ono spopularyzowane przez T. Khuna, socjologa nauki, który badając zagadnienie jej rozwoju, określił tym mianem "powszechnie uznawane osiągnięcia naukowe, które w pewnym czasie dostarczają społeczności uczonych modelowych problemów i rozwiązań" (Khun, 2001, s. 10). Termin ten znany był już w czasach starożytnych, etymologicznie zaś wywodzi się od greckiego pojęcia paradigma oznaczającego wzorzec, przykład, próbkę (Liddel, Scott, 1940). W kontekście szeroko pojętej edukacji, definiowanej na potrzeby artykułu jako zbiór praktyk społecznych zorganizowanych wokół idei przekazywania wiedzy, paradygmat używany będzie $\mathrm{w}$ jednym ze znaczeń nadanym mu przez C. Kupisiewicza, jako dominujący styl myślenia (Kupisiewicz, 1985). Analizując zmiany w obrębie tak rozumianej edukacji, należy przybliżyć pogląd T. Khuna na proces zmiany paradygmatycznej.

W przypadku nauki autor Struktury rewolucji naukowych stwierdza, iż zmiany dokonują się skokowo i przyjmują charakter rewolucji. Gdy nowe dane eksperymentalne nie mogą zostać wyjaśnione na gruncie istniejącej teorii, pojawia się potrzeba stworzenia nowego modelu wyjaśniania. Z czasem potrzeba ta staje się nagląca, a nauka wchodzi w fazę rewolucyjną, po której ustanowiony zostaje nowy paradygmat. Edukacji w nakreślonym znaczeniu nie pozwala na tego rodzaju postęp skokowy. Nie jest bowiem homogeniczną formacją, a konglomeratem różnych sądów i opinii. Podobnie jak nauki humanistyczne $\mathrm{w}$ znacznym stopniu fundująca edukacje od strony teoretycznej. Według Khuna, nauki humanistyczne są polisemiczne (multiparadygmatyczne), co oznacza, iż wiele różnych paradygmatów może funkcjonować w nich symultanicznie.

$\mathrm{Z}$ powyższych stwierdzeń wynikają dwie niezwykle istotne kwestie. Pierwsza, że zmiana paradygmatu analogiczna do obecnego w naukach empirycznych skokowego przejścia nie jest możliwa. Można tu mówić jedynie o pewnego rodzaju popularności, modzie, która sprawia, że dany nurt staje się dominujący. Tytułowe stwierdzenie dotyczące formowania się nowego paradygmatu w edukacji traktować zatem należy jako formowanie się pewnego frontu myślowego, który najprawdopodobniej stanie się $\mathrm{w}$ niedalekiej przyszłości dominujący. Druga kwestia pojawiająca się w związku z polisemicznością edukacji sprowadza się do stwierdzenia, iż o ile w naukach empirycznych nowy paradygmat oznacza zawsze postęp, to w naukach humanistycznych, a także szeroko rozumianej edukacji, możemy mówić jedynie o zmianie. Ta zaś niekoniecznie musi być pozytywna. 


\section{OBLICZA „NOWEGO ŁADU EDUKACYJNEGO”}

Nasuwa się zatem pytanie o przyczyny tytułowej transformacji. Wskazuje się tu cztery wzajemnie warunkujące się obszary, które bezpośrednio bądź pośrednio wpływają na istniejącą rzeczywistość edukacyjną (Kąkolewicz, 2009):

1. Przemiany technologiczne - technologie informatyczne i telekomunikacyjne, które zmieniają sposób komunikowania i dostępu do wiedzy.

2. Przemiany cywilizacyjne - rozwój społeczeństwa informacyjnego opartego na wiedzy, powstanie telepracy, jak i nowej klasy społecznej kognitariatu.

3. Zmiany kulturowe - zmiana sposobu uczestnictwa w kulturze poprzez powstanie nowych kanałów odbioru i dystrybucji, ale także zmiana struktury wytwórców kultury przez fenomen Web 2.0.

4. Transformacja struktur społecznych - zmiany w modelu rodziny i indywidualizm wyrastający ze zmian kulturowych.

Najistotniejsza jest jednak zmiana w obrębie technologii. Według założeń technologicznego determinizmu pojawienie się konkretnych technologii w sposób nieunikniony prowadzić musi do przemian cywilizacyjno-kulturowych, które - w przypadku naszej cywilizacji - wciąż trwają, a których efekty długofalowe pozostają wielką niewiadomą. Niemniej już dziś badania naukowe ujawniają, że technologia wpływa nie tylko na zmianę $\mathrm{w}$ obrębie praktyk społecznych, ale również w aspekcie fizjologicznym na mózg osób ją wykorzystujących, modyfikując działanie struktur odpowiedzialnych za pamięć i uwagę (Thomas, Benke, 2011; Kanai, Bahrami, 2011; Sparrow, 2011).

Jak zatem wyglądać może przyszły paradygmat edukacji? Potencjalne zmiany, jakie dziś można zaobserwować, dotyczą następujących obszarów:

1. Większe wykorzystanie technologii: zwiększanie się proporcji doświadczeń edukacyjnych zapośredniczonych technologicznie w stosunku do zajęć tradycyjnych.

2. Otwarty dostęp do wiedzy: dla każdego poziomu edukacji, a także $\mathrm{w}$ celach samokształcenia, nieograniczony dostęp do coraz bogatszej oferty darmowych zasobów edukacyjnych (OZE), a także artykułów naukowych (Open Access).

3. Indywidualne dopasowanie: zautomatyzowane systemy dopasowujące proces kształcenia odbywającego się w środowiskach zapośredniczonych technologicznie do indywidualnych predyspozycji i potrzeb ucznia (np. Khan Academy).

4. Globalne wspólnoty edukacyjne: grupy edukacyjne funkcjonujące globalnie, komercyjne bądź non profit. 
5. Descholaryzacja: odejście od edukacji formalnej na rzecz aktywności nieformalnych (w tym edukacji domowej) wykorzystujących w dużym stopniu darmowe zasoby wiedzy.

W dalszej części artykułu skupiono się głównie na kwestii otwartego dostępu do wiedzy.

\section{EKOSYSTEM OTWARTYCH ZASOBÓW EDUKACYJNYCH}

Według definicji OECD, OZE to cyfrowe, ogólnodostępne i darmowe materiały edukacyjne dostępne dla nauczycieli, studentów i osób zainteresowanych do wykorzystania $\mathrm{w}$ nauczaniu - uczeniu się i badaniach naukowych (OECD, 2007, s. 10). Termin po raz pierwszy użyty został w 2002 r. na konferencji UNESCO dotyczącej wpływu OZE na stan edukacji akademickiej. Od tego czasu stał się powszechnie stosowanym określeniem na tego typu zasoby. Raport OECD Giving Knowledge for Free: The Emergence of Open Educational Resources charakteryzuje następujące typy OZE:

- materiały dydaktyczne: pełne kursy, pojedyncze moduły, obiekty nauczania, kolekcje i czasopisma,

- narzędzia: oprogramowanie wspierające rozwój, korzystanie, ponowne wykorzystanie i udostępnianie materiałów dydaktycznych, a także wyszukiwanie i organizowanie treści, systemy zarządzania nauczaniem oraz wspólnoty uczące się online.

- zasoby wdrożeniowe: licencja prawa autorskiego umożliwiająca otwarte publikowanie materiałów, przykłady najlepszych praktyk tworzenia materiałów oraz przekładania ich na inny język.

Dwa ostatnie typy tworzą pewnego rodzaju fundament dla funkcjonowania osadzanej w nim warstwy treści. W efekcie powstaje komplementarny ekosystem, który pozwala na cały „cykl życiowy” OZE składający się na wyszukiwanie, adaptowanie, modyfikowanie i udostępnianie w sposób zgodny z prawem (Gurell, 2008). Warto przyjrzeć się bliżej konkretnym egzemplifikacjom funkcjonującym w obrębie wymienionych typów.

Najbardziej znanym przykładem udostępniania treści dydaktycznych jest inicjatywa Massachusetts Institute of Technology o nazwie OpenCourseware powstała w roku 2001. Na udostępnione materiały składają się sylabusy, skrypty zajęć, plany lekcji, ćwiczenia, ale również całe nagrania wykładów. Inicjatywa MIT była impulsem, który spowodował powstanie podobnych przedsięwzięć i wywołał międzynarodową dyskusję już w kolejnym roku. Efektem forum UNESCO w 2002 r. na temat wpływu OZE na edukację akademicką w krajach rozwijających się była konkluzja, iż otwarte zasoby edukacyjne są niezwykle istotne dla współczesnych społeczeństw, 
ponieważ wiedza jest w nich główną siłą katalizującą zmiany (UNESCO, 2002). Samo zaś przedsięwzięcie MIT rozrosło się do rozmiarów międzynarodowego konsorcjum, które w 2011 r. skupiało ponad 250 instytucji akademickich udostępniających łącznie ponad 15000 zasobów edukacyjnych (MIT, 2011).

Wśród narzędzi związanych z rozwojem, utrzymaniem i wyszukiwaniem OZE wyróżnić można dziesiątki różnych aplikacji, systemów czy portali. Są wśród nich narzędzia open Skurce, między innymi do tworzenia treści dydaktycznych (eXe, wink), platformy e-learningowe (Moodle, Ilias, Atuor etc.), a także systemy udostępniania otwartych zasobów (eduCommons). Szczególną uwagę należy zwrócić na przedsięwzięcia, które są odpowiedzią na pytanie: Jak dotrzeć na OZE? Okazuję się, że najczęściej używane wyszukiwarki internetowe podają $\mathrm{w}$ wynikach zaledwie ułamek dostępnych w sieci zasobów. W związku z tym istnieje konieczność utworzenia scentralizowanych katalogów, które specjalizują się w śledzeniu na bieżąco dostępnych treści edukacyjnych i stale aktualizują swoje bazy danych. Projektem tego typu są między innymi OER Commons project Study of Knowledge Management in Education <www.oercommons.org > i niedziałający projekt autora niniejszego artykułu - OAZE <oaze.edu.pl>. Systemy tego typu poza wyszukiwaniem interesujących zasobów pozwalają również na wystawienie oceny bądź publikowanie komentarzy. W przypadku wielości zasobów o podobnej tematyce informacja zwrotna znacznie ułatwia selekcję najlepszych z nich.

Ostatnim typem OZE są otwarte/wolne licencje, które tworzą prawną podstawę do udostępniania treści w sieci. Stanowią one element liberalnego modelu praw autorskich, który sprzeciwia się panującemu obecnie restrykcyjnemu podejściu do tej kwestii (Lessing, 2004). Istnieje ponad dziesięć rodzajów otwartych/wolnych licencji, które zastosować można do różnego rodzaju twórczości - utworów muzycznych, oprogramowania czy sztuki (Liang, 2004). Najczęściej używane są jednak licencje GPL oraz Creative Commons. O ile pierwsza dotyczy niemal wyłącznie oprogramowania, druga może zostać użyta do każdego dzieła kultury. Możliwość regulacji stopnia „udostępniania” danego dzieła na licencji CC sprawiła, że stała się ona najpowszechniej używaną licencją.

\section{OZE A KSZTAŁT NOWEGO PARADYGMATU}

Otwarte Zasoby Edukacyjne to fenomen, który oddziałuje na wielu płaszczyznach szeroko rozumianej edukacji. Stwarza też zupełnie nowe możliwości nabywania wiedzy i kompetencji, zwłaszcza w obszarze auto- 
edukacji i edukacji domowej. Z punktu widzenia tytułowego założenia wpływu OZE na kształtowanie się nowego „dominującego sposobu myślenia" - wyróżnić należy cztery kluczowe momenty, które warunkować mogą kształt przyszłego ładu edukacyjnego zarówno w obrębie formalnej, jak i nieformalnej edukacji. Dodać należy, że idea otwartości stanowi punkt wyjścia dla wszystkich z nich.

1. Demokratyzacja środków dydaktycznych. Działalność edukacyjna wiąże się niemal zawsze z wykorzystywaniem środków dydaktycznych. W edukacji formalnej najistotniejszym wciąż pozostaje podręcznik, który nakreśla merytoryczną podstawę przeprowadzanych zajęć. W tradycyjnym sposobie ich wytwarzania istnieje klasyczny wolnorynkowy podział na wytwórców (wydawnictwa) oraz konsumentów (nauczycieli i uczniów). OZE wprowadzają alternatywny, otwarty model wytwarzania i dystrybucji środków dydaktycznych, w którym zarówno nauczyciel, jak i uczeń mają możliwość wpływania na kształt podręcznika oraz innych środków dydaktycznych.

Tego rodzaju podręczniki (opentextbooks) stanowić mają alternatywę dla tradycyjnych odpowiedników, których cena niejednokrotnie przerasta możliwości finansowe gorzej sytuowanych rodzin. Korzyść społeczna w postaci wyrównania szans uczących się osób jest widoczna głównie na poziomie edukacji szkolnej. Jednym z najgłośniejszych przedsięwzięć w tym zakresie jest California's Digital Textbook Initiative. Stworzony w 2009 r. projekt był pierwszą tego typu akcją na terenie Stanów Zjednoczonych i stanowił bezpośrednią reakcję na kryzys ekonomiczny stanu Kalifornia. W efekcie powstało szesnaście podręczników szkolnych stworzonych przez nauczycieli wolontariuszy, z których dziesięć zrealizowało wymagane standardy w 90\%, cztery zaś w 100\%. Do końca 2013 r. ma powstać łącznie pięćdziesiąt wolno dostępnych podręczników wysokiej jakości. Również w Polsce znaleźć można przykład realizacji tej idei. Portal <wolnelektury.pl>, stworzony przez Fundację Nowoczesna Polska, jest platformą do współtworzenia przez nauczycieli społeczników podręczników szkolnych. Choć przedsięwzięcie to nie przyniosło jednak, jak na razie, wymiernych rezultatów, spowodowało zakorzenienie się samej idei, która istotnie oddziałuję na politykę ministerstwa edukacji (np. w kwestii licencjonowania e-podręczników).

Poza podręcznikami istnieją również narzędzia pozwalające nauczycielom współtworzyć i wymieniać się pomocami dydaktycznymi. Przykładami godnymi odnotowania są platformy Connexions oraz Wikiversity. Projekt Uniwersytetu w Rice, Connexions, liczył w czerwcu 2013 r. ponad 22000 modułów wiedzy i stanowił największą na świece platformę tego typu. $\mathrm{Z}$ kolei projekt fundacji Wikimedia, Wikiuniversity, w wersji anglojęzycznej 
liczył łącznie ponad 19000 artykułów o charakterze edukacyjnym. Liczby te ukazują, jak ogromny potencjał drzemie w globalnej społeczności osób zorientowanych na współtworzenie edukacji.

2. Globalna, oddolna debata nad edukacją. Znaczenie edukacji dla współczesnych społeczeństw opartych na wiedzy jest nie do przecenienia. Od wczesnych lat 70. edukacja jest tematem międzynarodowej dyskusji uważanym za niezwykle relewantny dla rozwoju oraz dobrobytu cywilizacyjnego i indywidualnego, o czym świadczą chociażby raporty Faure'a czy Delorsa. Dyskusja ta dotychczas miała charakter stricte ekspercki, stąd udział w niej był dla większości niemożliwy. Dzięki fenomenowi OZE w 2005 r. UNESCO powołało globalną wspólnotę (OER Community), do której dołączyć mógł każdy i w której głos eksperta był na równi traktowany z głosem nauczyciela z prowincji. Poza społecznością UNESCO zagadnienie otwartych zasobów i edukacji w ogóle było w centrum zainteresowania wielu organizacji pozarządowych. Osiągnięta w rezultacie masa krytyczna doprowadziła to stworzenia w 2008 r. Kapsztadzkiej Deklaracja Otwartej Edukacji. Ten globalny, oddolny manifest artykułuje potrzebę wspólnego wysiłku osób zainteresowanych edukacją na rzecz stworzenia nowego paradygmatu w edukacji wyrosłego z kultury daru (KDOE, 2008). W Polsce deklaracja została przyjęta z entuzjazmem i zaledwie parę miesięcy po jej ogłoszeniu powstała Koalicja Otwartej Edukacji skupiająca jednostki akademickie i organizacje pozarządowe, której działania wpływają w sposób istotny na politykę edukacyjną Ministerstwa.

3. Nowe możliwości formalnej/nieformalnej edukacji. OZE to nie tylko alternatywny model wytwarzania środków dydaktycznych czy katalizator globalnej dyskusji nad edukacją, ale również zupełnie nowe możliwości zdobywania wiedzy i kompetencji. Możliwości, które, jak stwierdza raport OECD, powodują zacieranie granic pomiędzy formalnym a nieformalnym nauczaniem - uczeniem się (OECD, 2007). Warto tu nadmienić dwa rodzaje przedsięwzięć. Do pierwszego z nich należą kursy MOOC (Massive open online course) dostępne na platformach Udacity, Coursera, edX czy Venture Lab. To najczęściej całkowicie zautomatyzowane, darmowe kursy odbywające się $\mathrm{w}$ ściśle określonym czasie, prowadzone przez akademików z najlepszych uczelni świata. Dodatkowo uzyskaną dzięki nim wiedzę można coraz częściej potwierdzić płatnym certyfikatem, na przykład w kursach z serii MITx (MITnews, 2011). Należy zauważyć, że certyfikaty tego typu uzyskują dziś akredytacje coraz większej liczby instytucji akademickich. W praktyce oznacza to, iż w przypadku gdy ich posiadacz jest studentem, pozwalają one uzyskać zwolnienie z odpowiadającego na studiach przedmiotu (Young, 2012). 
Do novum należą również próby tworzenia globalnych wspólnot edukacyjnych o płaskiej strukturze. Takim przedsięwzięciem jest p2p University <p2pu.org>, który w wirtualnej przestrzeni daje każdemu możliwość stania się wykładowcą i prowadzenia kursu z wybranej tematyki, a także uczestniczenie $\mathrm{w}$ oferowanych na platformie zajęciach.

4. Rewitalizacja aksjologicznego fundamentu edukacji. Gdy w 2001 r. MIT udostępniło swoje cyfrowe zasoby, "New York Times” poświęcił temu wydarzeniu swoją pierwszą stronę. W artykule ówczesny prezydent MIT Charles Vest stwierdził, iż udostępnienie zasobów edukacyjnych może wyzwolić kreatywność niemożliwą do osiągnięcia w zamkniętych systemach (Goldberg, 2001). Wartość, jaką jest powszechny dostęp do edukacji, została tu pogodzona z celem ekonomicznym komercyjnego przedsięwzięcia. Pomimo iż stanowisko MIT może być tłumaczone strategią marketingową, stanowiło ono precedens, którego efektem było społeczne przewartościowanie postaw dotyczących zagadnienia dostępności wiedzy i edukacji. Kilka lat później Koïchiro Matsuura, dyrektor generalny UNESCO, stwierdził, iż: „By pozostać ludzkimi i zdatnymi do życia, społeczeństwa wiedzy będą musiały stać się społeczeństwami dzielącymi się wiedzą" (UNESCO, 2005). Możliwość uczenia się od najlepszych sprawia, że dochodzi do globalnego równania w górę i zmniejszania się dysproporcji społecznych. Sytuacja, która jeszcze nieco ponad dekadę temu była niemożliwa do zrealizowania, dziś jest wręcz koniecznością, a dla państw rozwiniętych wręcz imperatywem etycznym do zrealizowania. Nowy paradygmat $\mathrm{w}$ edukacji z pewnością opierać się będzie na kulturze daru, która przyczyniła się do rewitalizacji immanentnych wartości, jakie edukacja niesie z sobą co najmniej od okresu oświecenia.

\section{LITERATURA}

Kąkolewicz M., Technologie informacyjne a konieczność zmiany paradygmatów edukacji, [w:] M. Dąbrowski, M. Zając (red.), Koncepcje i praktyka e-edukacji, Fundacja Promocji i Akredytacji Kierunków Ekonomicznych, Warszawa 2011, s. 24-33.

Khun T.S., The structure of scientific revolutions, Aletheia, Warszawa 2001.

Kupisiewicz C., Paradygmaty i wizje reform oświatowych, Wyd. Akad. Żak, Warszawa 1994. Liddell H.G., Scott R., A Greek-English Lexicon, Clarendon Press, Oxford 1940.

Sparrow B., Liu J., Wagner D.M., Google Effects on Memory: Cognitive Consequences of Having Information at Our Fingertips, "Science” 2011, Vol. 333, No. 6043.

Thomas S., Benke G.P., Dimitriadis C., Inyang I., Sim M., Wolfe R., Croft R.J., Abramson M.J., Use of mobile phones and changes in cognitive function in adolescents, "Occupational and Environmental Medicine" 2011, 67(12). 


\section{NETOGRAFIA}

Goldberg C. 2001. Auditing classes at M.I.T., on the web and free, "The New York Times”, <http://www.nytimes.com/2001/04/04/technology/04MIT.html?pagewanted=1>, [dostęp: 25.06.2013].

Gurell S. 2008. OER Handbook for Educators 1.0, The Center for Open and Sustainable Learning, <http://www.wikieducator.org/OER_Handbook/educator_version_one>, [dostęp: 25.06.2013].

Kanai R., Bahrami B., Roylance R., Rees G. 2011. [On-line] social network size is reflected in human brain structure, Proceedings of the Royal Society B: Biological Sciences, <http:/ / rspb.royalsocietypublishing.org/content/early/2011/10/12/rspb.2011.195 9.full>, [dostęp: 25.06.2013].

Kapsztadzka Deklaracja Otwartej Edukacji, 2008. <http://www.capetowndeclaration. org/translations/translations/polish-translation>, [dostęp: 25.06.2013].

Lessing L. 2004. Free Culture, The Penguin Press, <http://www.free-culture.cc/free culture.pdf>, [dostęp: 25.06.2013].

Liang L. 2004. A Guide To Open Content Licences, Piet Zwart Institute, <http://pzwart. wdka.hro.nl/mdr/research/lliang/open_content_guide>, [dostęp: 25.06.2013].

MIT, 2011. OCW Summary report 2011, <http://ocw.mit.edu/about/site-statistics/ 11_Eval_Summary_112311_MITOCW.pdf>, [dostęp: 25.06.2013].

MITnews, 2011. MIT launches [On-line] learning initiative, <http://web.mit.edu/ newsoffice/2011/mitx-education-initiative-1219.html>, [dostęp: 25.06.2013].

OECD, 2007. Giving knowledge for free: the emergence of Open Educational Resources, Paris: OECD, <http://www.oecd.org/edu/ceri/38654317.pdf/>, [dostęp: 25.06.2013].

UNESCO, 2002. Forum on the impact of open courseware for higher education in developing countries: final report, Paris: UNESCO, <http://unesdoc.unesco.org/images/ 0012/001285/128515e.pdf>, [dostęp: 25.06.2013].

UNESCO, 2005. Towards knowledge societies, UNESCO world report. Paris: UNESCO, <http://unesdoc.unesco.org/images/0014/001418/141843e.pdf>, [dostęp: 25.06. 2013].

Young J. 2012. American Council on Education May Recommend Some Coursera Offerings for College Credit, The Cronicle of Higher Education, 12 listopad, <http://chronicle. com/article/MOOCs-Take-a-Major-Step/135750/>, [dostęp: 25.06.2013]. 